\title{
RUMAH WISATA BULUTANGKIS
}

\author{
Yohanes Santoso ${ }^{1)}$, Alvin Hadiwono ${ }^{2)}$ \\ 1) Program Studi S1 Arsitektur, Fakultas Teknik, Universitas Tarumanagara, yohanes88188@gmail.com \\ 2) Program Studi S1 Arsitektur, Fakultas Teknik, Universitas Tarumanagara, alvinhadiwono@ymail.com
}

\begin{abstract}
Abstrak
Olahraga bulutangkis merupakan olahraga yang sangat dikenal masyarakat luas setelah sepak bola. Bulutangkis di Indonesia sendiri adalah salah satu pesaing yang selalu diunggulkan di kejuaraan tingkat dunia. Peran masyarakat dalam membentuk mental juara adalah hal yang sangat penting terutama dalam pencarian bibit unggul untuk regenerasi.Berbagai prestasi telah diraih oleh para atlet bulutangkis Indonesia, namun sangat di sayangkan prestasi tersebut belum membuat masyarakat dan pemerintah untuk menghargai secara lebih dengan apa yang telah diraih. Sejarah dan prestasi merupakan sebuah momentum yang harus diabadikan dan di turunkan kepada penerus bangsa Indonesia. Pada proyek "Badminton Touris, House " akan memadukan program arsitektur dengan wisata olahraga dan diharapkan dapat mewadahi semua kenangan tersebut sehingga dapat dipelajari dan juga tidak sirna dengan waktu.
\end{abstract}

Kata kunci : Rumah, wisata, bulutangkis, sejarah

\begin{abstract}
Badminton is one of the World most famous sport after football. Indonesia's badminton is considered as world class. The society has important role in building champion mentality and helps Indonesia to found best athletes for the regenerationThere are many achievements have been achieved by Indonesian athletes. However, their achievements were not appreciated by the society and the goverment. Achievements and histories made by the athletes should be seen by the next generations. This project "Badminton Tourist House" is combination of architectural programme and sport tourism. It is expected to be a place that can accomodate the histories of badminton. Therfore the society can learn about badminton and its history from this place
\end{abstract}

Keyword : badminton, house, tourism, history

\section{PENDAHULUAN}

Gaya hidup yang ingin serba instan seperti halnya makanan cepat saji , diet tidak sehat, malas berolahraga memicu berbagai penyakit terutama Obesitas. Selain Kerasnya hidup dan padatnya aktivitas dapat memicu terjadinya stress. Tetapi jika anda berolahraga dendan teratur maka tidak akan terkena stress. Selain itu tubuh akan lebih sehat jika kita tidak mengalami stress karena banyak sekali penyakit yang diawali dengan stress. Pikiran juga akan tetap fresh dengan olahraga.

Selain dengan olahraga pola makan yang sehat menjadi hal yang penting. Nutrisi yang tepat dalam berolahraga merupakan sebuah point tambahan untuk menjadikan tubuh yang sehat dan bugar. Olahraga dan kesehatan adalah dua hal yang berbeda namun memiliki keterikatan yang sangat erat. Kesehatan dapat diraih dengan pola hidup teratur, istirahat teratur dan olahraga teratur. Kesehatan akan dapat menciptakan hidup yang lebih bahagia lagi.

Data Badan Pusat Statistik 2015 menunjukkan, jumlah masyarakat Indonesia yang rutin berolahraga hanya $27,61 \%$, atau bisa dibilang masyarakat Indonesia yang rutin berolahraga (minimal satu kali seminggu) belum mencapai sepertiga jumlah penduduk Indonesia. Dalam arti lain, dari 100 penduduk Indonesia hanya ada 28 orang yang rutin melakukan aktivitas fisik secara rutin. 


\section{KAJIAN LITERATUR}

Menurut Andersen (1999) pada umumnya, kapasitas fungsional latihan dimulai dari $40-85$ $\%$. Orang dengan dengan permasalahan jantung berbeda dengan yang normal, kapasitas fungsional intensitas latihan ditetapkan antara 40 sampai dengan $60 \%$. Durasi latihan atau ketahanan dapat ditetapkan sesuai dengan respon tubuh seseorang terhadap latihan. Olahraga merupakan bagian penting untuk tubuh yang tidak dapat terpisahkan dari upaya peningkatan kesehatan dan kebugaran agar tubuh optimal. Hanya saja olahraga harus dilaksanakan sesuai dengan pedoman yang tepat agar tujuan untuk mendapat tubuh yang ideal dan bugar dapat tercapai dengan mudah. Hal tersebut meliputi penentuan intensitas, durasi, frekuensi, jenis serta progresi latihan yang tepat.

Obesitas terjadi ketika tubuh menerima atau mengkonsumsi lebih banyak kalori daripada membakar kalori. Hal itu disebabkan oleh banyak faktor lainnya seperti genetik. Genetik memang dapat membuat seseorang menjadi obesitas tetapi itu bukanlah hal yang utama. Faktor lingkungan dan perilaku memiliki pengaruh yang cukup besar, makanan yang tinggi lemak dan sedikit sekali melakukan ativitas fisik atau tidak setiap hari berolaharaga dalam jangka waktu yang lama akan menyebabkan penambahan berat badan.

Faktor psikologis juga dapat menyebabkan obesitas. Perasaan rendah diri, rasa bersalah, stres, emosional, atau trauma juga dapat memicu seseorang untuk mengkonsumsi makanan secara berlebihan. Berdasarkan Lembaga Skala Survei Indonesia bulutangkis adalah salah satu cabang olahraga yang digemari oleh masyarakat Indonesia setelah sepak bola yang masih menjadi nomor 1 sebagai olahraga yang paling banyak diminati masyarakat Indonesia bahkan dunia. Selain itu Bulutangkis juga diminati oleh segala gender dibandingkan sepak bola yang penggemar utamanya kaum laki - laki.

Bulutangkis di Indonesia memulai eksistensinya pada tahun 1930an yang dianungi oleh Ikatan Sport Indonesia (ISI). Setelah tanggal 5 Mei 1951 organisasi dengan nama Persatuan Bulu Tangkis Seluruh Indonesia (PBSI) mulai terbentuk. Sekitar tahun 1961 tim bulu tangkis Indonesia berhasil merebut gelar juara, dan kemudian pada ajang piala Thomas tahun 1964 di Tokyo, Jepang, Indonesia berhasil kembali menjadi juara. Bulutangkis Indonesia merupakan salah satu pesaing terkuat di dunia, dimana para pemainya tidak bisa di remehkan. Badminton Tourism House adalah tempat dimana kenangan para pemain disimpan sebagai memori sekaligus semangat untuk pengingat generasi selanjutnya.

\section{METODE}

Penelitian ini dilakukan dengan metode literatur, studi preseden dan pengamatan . Pengamatan dilakukan langsung di lokasi tapak dan lingkungan sekitarnya, untuk mendapatkan data-data statistik dan tertulis berkaitan dengan isu yang dibahas sebagai bukti bahwa proyek layak dan dibutuhkan masyarakat. Untuk mendapatkan pengertian dasar mengenai hal-hal yang menjadi kata kunci pada proyek yang akan dirancang. Untuk mendapatkan teori-teori yang dapat menjadi landasan untuk diterapkan pada proyek. Untuk mendapatkan standard yang perlu dipenuhi dalam proses merancang nantinya. Untuk mengetahui persyaratan apa saja yang akan dibutuhkan dalam perancangan proyek ini. Untuk mempelajari tipologi dari proyek sejenis, membandingkan proyek sejenis dan untuk mengetahui bagaimana proyek sejenis dapat mewadahi wisata olahraga bulutangkis. Serta menarik kesimpulan dari proyek sejenis untuk menjadi inspirasi.

\section{DISKUSI DAN HASIL}

\section{Bulutangkis Sebagai Wisata}

Sampai saat ini banyak sekali penghargaan yang telah diarih Indonesia melalui bulutangkis baik individu maupun grup seperti piala Thomas cup dan Uber cup di ajang internasional. 
Nama- nama seperti Rudy Hartono, Alan Budi Kusuma, Susy Susanti merupakan contoh kebanggaan masyarakat Indonesia. Bahkan Rudy Hartono masuk kedalam Guinnes book of record dengan meraih juara all England terbanyak. Beliau juga dijadikan salah satu patung lilin di madame Tussauds Singapura. Sayangnya di Indonesia tidak memiliki tempat untuk menyimpan semua hal tersebut.

Komunitas pecinta bulutangkis dan masyarakat seharusnya memiliki tempat tersendiri untuk euphoria dari kejayaan bulutangkis Indonesia. Diharapkan ada wadah menjadi pengingat sekaligus memupuk rasa nasionalisme masyarakat Indonesia untuk terus mengharumkan nama Indonesia melalui olahraga bulutangkis. Edukasi yang diberikan sejak dini diyakini dapat melahirkan bibit yang unggul.

Wadah yang diharapkan merupakan tempat pengunjung dapat melakukan wisata edukasi dan olahraga sekaligus untuk menghilangkan stress. Selain itu pengunjung dapat mengkonsultasikan nutrisi untuk mencapai tubuh yang ideal sertanutrisi yang tepat. Indonesia yang memiliki banyak sejarah kemenangan mempunyai kewajiban untuk mempertahankan kejayaan tersebut melalui pembinaan atlet muda dan tidak hanya sampai disitu mental para pemain juga harus dibangun dengan baik. Salah satunya dengan mendirikan tempat dimana memori kebanggaan disimpan dan dijadikan tolok ukur para pemain sehingga mereka memiliki daya juang yang lebih dari pemain lainya.

\section{Tujuan Proyek}

Dari masalah yang didapat, peneliti menentukan tujuan yang ingin dicapai dari proyek yang dirancang ini, yaitu memfasilitasi masyarakat untuk dapat berolahraga dan menjaga asupan untuk tubuh, menjadikan wadah bagi masyarakat khususnya pecinta bulutangkis untuk dapat lebih mengenal mengenai bulutangkis dan sejarahnya, menjadi tempat untuk apresiasi para atlet bulutangkis Indonesia dan bulutangkis di Indonesia perlu mendapat perhatian khusus dan perlu ada proyek yang pas untuk menangani masalah ini sehingga wisata olahraga di kota metropolis dapat terwujud.

\section{Konsep Perancangan dengan Pendekatan Metode Desain Movement}

Wisata dapat diartikan bepergian bersama-sama (untuk memperluas pengetahuan, bersenang-senang, dan sebagainya). Sedangkan bulutangkis adalah olahraga raket yang dimainkan oleh dua orang atau dua pasangan yang saling berlawanan. Sehingga dapat ditarik kesimpulan wisata bulutangkis merupakan kegiatan yang dilakukan seseorang atau lebih untuk berpergian untuk memperluas pengetahuan, bersenang-senang dengan hal yang berkaitan dengan bulutangkis.

Rumah memiliki banyak sekali makna, dapat diartikan tempat tinggal, tempat singgah, namun dapat juga diartikan sebagai tempat atau wadah sebuah kegiatan. Rumah wisata bulutangkis sendiri adalah tempat atau wadah kegiatan yang dilakukan seseorang atau lebih untuk berpergian untuk memperluas pengetahuan, bersenang-senang dengan hal yang berkaitan dengan bulutangkis.

Segala sesuatu mengenai bulutangkis hadir dan dapat dirasakan oleh seseorang dirumah wisata bulutangkis. Pada perancangan Badminton Tourism House digunakan metode design movement. Design movement yang digunakan untuk menerjemahkan pergerakan atau teknik bermain bulutangkis ke dalam bentuk arsitektur. 

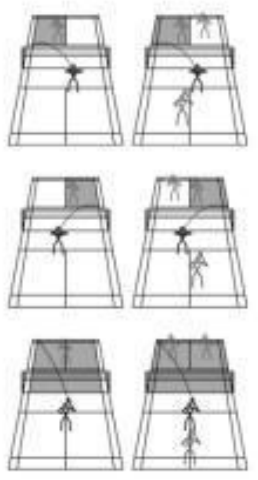

Gambar 1. Pola Permainan Bulutangkis

Sumber: aturanpermainan.blogspot.com

Pola pergerakan pemain bulutangkis di area lapangan bulutangkis merupakan hal yang dapat diamati. Saat pemain melakukan pertandingan single seorang pemain akan berdiri dengan berjaga jaga diarea tengah lapangan. Hal ini ditujukan agar memudahkan pengambilan bola agar dapat dikembalikan ke area musuh. Pada permainan ganda juga hampir sama kedua pemain akan membuat area tersendiri untuk dapat menjangkau bola yang menjadi tanggung jawab pemain tersebut.

Pola tersebut membentuk linear yang teratur, saat bola jatuh diarea depan kiri pemain akan melangkah dengan langkah kakinya dan kembali ke posisi semula dengan langkah kaki yang sama. Pola tersebut diangkat penulis menjadi poros pada bangunan untuk dijadikan linear massa.

\section{Program Wisata Bulutangkis}

Kegiatan yang ada di tapak merupakan program campuran yaitu olahraga yang dibungkus dengan rekreasi. Program yang ditawarkan merupakan gabungan antara olahraga dengan wisata sehingga berbeda dengan sport hall atau yang dikenal dengan gelanggang olahraga. Adapun Program yang ditawarkan berbeda dengan gelanggang olahraga pada umumnya, seperti virtual badminton, technical badminton, legend vision, learning experience, hall of fame, gallery dan penunjang lainnya.

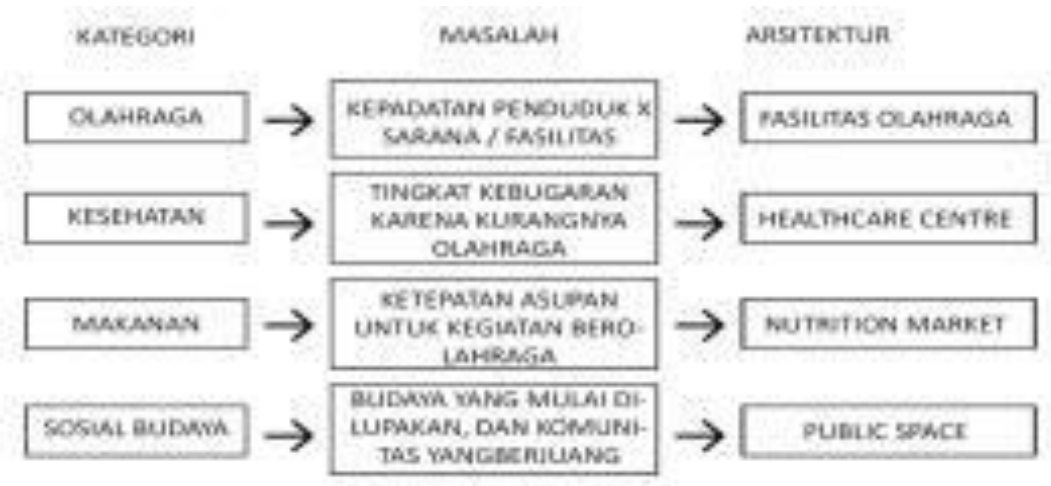

Gambar 2. Skema pemikiran

Sumber: Pribadi

Virtual badminton merupakan olahraga bulutangkis yang di kembangkan oleh yonex (salah satu produsen alat-alat bulutangkis). Virtual badminton memungkinkan pengunjung dapat merasakan bermain Bersama dengan idola mereka baik single maupun double. The Legend vision merupakan salah satu program yang diadakan untuk kampanye baik untuk acara amal atau pun jumpa fans para atlet dengan pendukung mereka, pada program ini juga 
memungkinkan pengunjung bermain secara real dengan pemain bintang. Technical Badminton merupakan tempat dimana pengunjung dapat mempelajari teknik dasar bermain sekaligus terdapat program dimana pemain dapat merasakan seberapa kuat pukulan para pemain bintang.

Galery dan hall of fame merupakan tempat berbagai memori, sejarah, dan berbagai prestasi pemain akan di pajang sebagai pengingat sekaligus penyemangat baik para atlet maupun bibit pemain. Selain itu terdapat berbagai program penunjang seperti restaurant untuk menunjang makan dari pengunjung. Amphiteater sebagai tempat pertunjukan dan sekaligus dapat digunakan sebagai tempat untuk nonton pertandingan bersama. Make your own shuttlecock dimana pengunjung dapat membuat kok sendiri dengan alat.

\section{Tapak di Kawasan Menteng}

Lokasi tapak ber seberangan dengan monument Tugu Tani yang merupakan tempat yang sudah kumuh dan tidak terawat, dahulunya lokasi ini merupakan tempat percetakan yang sampai saat ini di beberapa lokasi masih digunakan sebagai percetakan. Alamat berada di Jalan Menteng Raya No. 24C, RT 01/RW 07, Kebon Sirih, Menteng, Kota Jakarta Pusat, Daerah Khusus Ibukota Jakarta 10340. Luas Tapak 4.069 m2. KDB 60\%. KLB 1.8. KTB 55\%. KDH 30\%. KB 5. Zonasi Campuran C1. GSB 5 m.

\section{Kesesuaian Proyek dengan Peraturan Pemerintah}

Proyek dirancang berdasarkan peraturan dari pemerintah, salah satunya dalam hal luasan bangunan. Berikut ini merupakan tabel luas lantai bangunan.

Tabel 1. Luas Lantai Bangunan

\begin{tabular}{|c|c|c|}
\hline No & Lantai & $\begin{array}{c}\text { Luas } \\
\text { (dalam } \mathbf{~ m}^{\mathbf{2}} \text { ) }\end{array}$ \\
\hline 1 & Lt. Satu & 1785 \\
\hline 2 & Lt. Dua & 1023 \\
\hline 3 & Lt. Tiga & 1023 \\
\hline 4 & Lt. Empat & 1023 \\
\hline 5 & Lt. Lima & 1023 \\
\hline 5 & Basement & 912 \\
\hline \multicolumn{2}{|c|}{ Total Luas (tanpa basement) } & $\mathbf{5 8 7 7}$ \\
\hline \multicolumn{2}{|c|}{ Total Luas (dengan basement) } & $\mathbf{6 7 8 9}$ \\
\hline
\end{tabular}

Sumber: Pribadi

\section{Badminton Tourism House}

Pembagian per lantai dengan lantai 1 merupakan main hall tempat menerima pengunjung, dan program merchandise store dan restaurant sebagai penunjang. Pada lantai kedua merupakan techinal badminton disini pengunjung dapat mempelajari Teknik bermain yang baik dan pengalaman dilatih oleh professional. Pada lantai ke tiga dan ke empat merupakan tempat display dan menyimpan sejarah badminton Indonesia dan dunia.

Segala mengenai bulutangkis ada disana. Pada lantai kelima terdapat virtual badminton dan juga the legend vision, pada dasarnya sama dengan lapangan bulutangkis pada umunya hanya saja ditambahkan teknologi AR. 


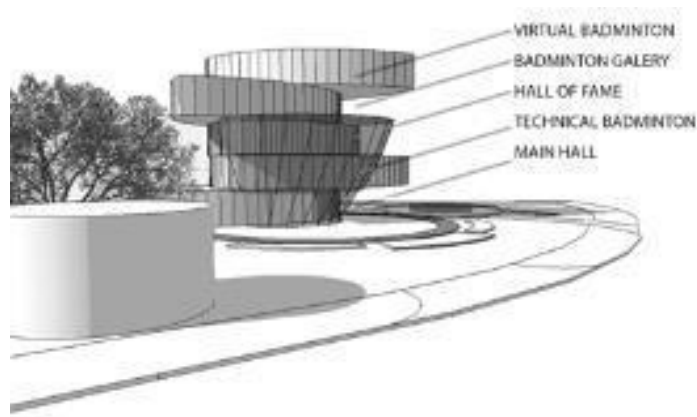

Gambar 3. Massa Bangunan

Sumber: Analisis Pribadi

\section{KESIMPULAN DAN SARAN}

Setelah melalui berbagai tahap dalam proses pengembangan proyek hingga desain akhir, penulis mendapatkan beberapa kesimpulan dan saran akhir. Isu yang diangkat dan melatarbelakangi proyek ini merupakan suatu fenomena yang memerlukan sebuah solusi sebagai tempat atua wadah wisata olahraga bulutangkis. Melalui berbagai analisis dan studi, dapat disimpulkan bahwa bulutangkis di Indonesia perlu mendapat perhatian khusus dan perlu ada proyek yang pas untuk menangani masalah ini sehingga wisata olahraga di kota metropolis dapat terwujud, bentuk, material, dan warna akan menggambarkan isi dari proyek itu sendiri sehingga perlu diperhatikan dalam proses desain. Lingkungan sekitar sangat mempengaruhi tapak dan hasil desain sehingga perlu mendapat tanggapan desain. Proyek ini dapat menjadi ikon baru bagi kota Jakarta karena belum ada sebelumnya sehingga dapat menarik wisatawan untuk berwisata dan menjadi wajah baru bagi kota metropolis Jakarta.

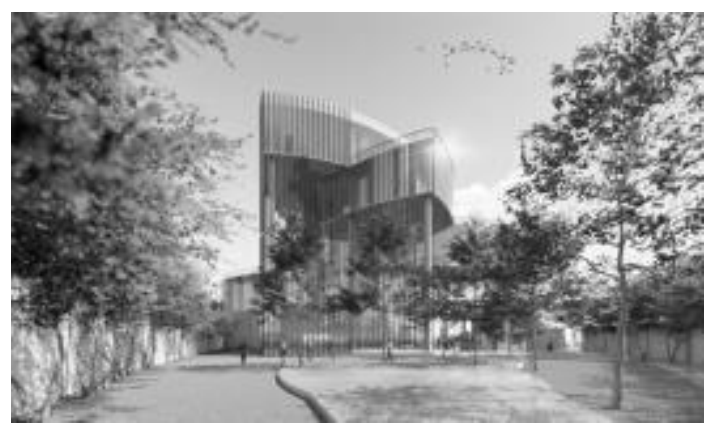

Gambar 4. Exterior

Sumber: Pribadi

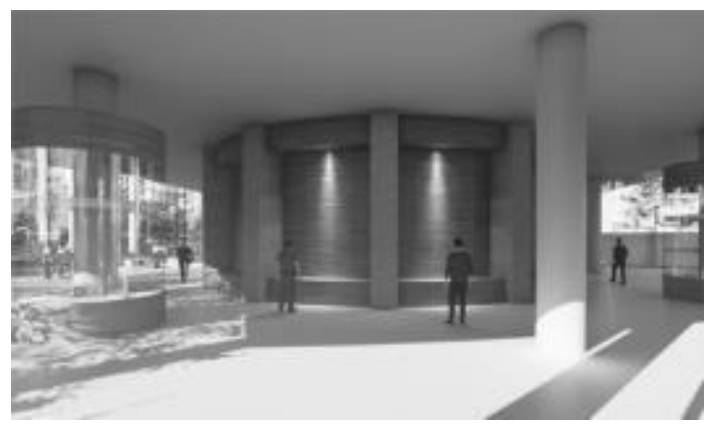

Gambar 5.Ruang Display

Sumber: Pribadi 


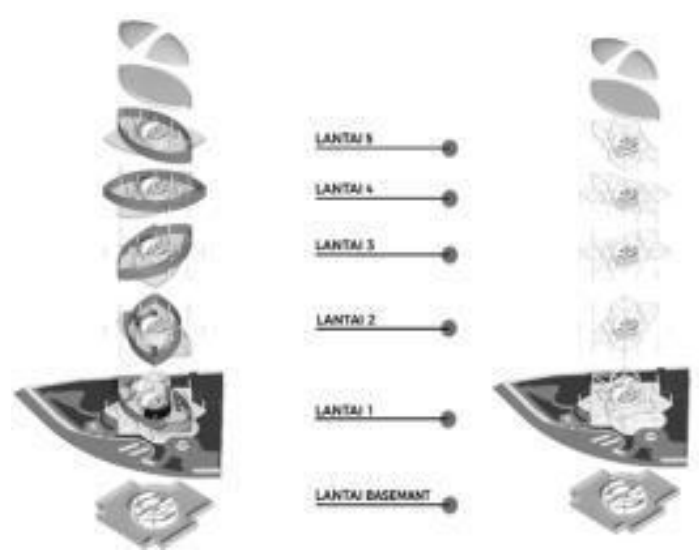

Gambar 6. Struktur Bangunan

Sumber: Pribadi

\section{UCAPAN TERIMA KASIH}

Dalam penelitian dan perancangan proyek Rumah Wisata Bulutangkis di Menteng ini, peneliti ingin menyampaikan ucapan terima kasih kepada pihak yang mendukung dan membimbing dalam proses yang dilakukan.

\section{REFERENSI}

Alexander, Christopher. (1997). A Pattern Language: Towns, Buildings, Construction. Oxford: Oxford University Press.

Badan Pusat Statistik. (2017). Provinsi Jakarta Dalam Angka 2017. Jakarta : Badan Pusat Statistik

Neufert, Ernst dan Peter Neufert. (2012). Architect's Data: Fourth Edition, Oxford: Blackwell Publishing.

Panero, Julius dan Martin Zelnik. (2003). Dimensi Manusia dan Ruang Interior. Jakarta: Erlangga.

Specht, Jan (2014) Architectural Tourism Building for Urabn Travel Destination, Gabler Verlag. Antara Sumbar, Menkes Serukan Olahraga Sebagai Gaya hidup

(http://www.antarasumbar.com/berita/190751/menkes---serukan---olahraga---sebagai--gaya---hidup.htmlJakarta )

Badmintalk, Venue Bulutangkis Terbaik

(http://badmintalk.com/news/Ini-Dia-Venue-Bulutangkis-Terbaik-di-Dunia-BagaimanaDengan-Istora.htm)

Jakart.bps, Statistik DKI Jakarta

(http://jakarta.bps.go.id/backend/pdf_publikasi/Statistik---Daerah------Provinsi---DKI--Jakarta---2014.pdf)

Linkedin, Importance : Physical Planning \& National Development Of Singapore . . . . . a model for Jakarta?

(https://www.linkedin.com/pulse/physical-planning-national-development-singaporeraymond-tirtawijaya?trk=portfolio_article-card_title)

New York Times: Something Needed to Play the Game Available : (https://www.nytimes.com/2017/05/09/crosswords/something-needed-to-play-thegame.html?rref=collection\%2Ftimestopic\%2FBadminton) 